\title{
Intenções e ações em torno dos programas UPP e Morar Carioca
}

Ricarda Lucilia Domingues Tavares ${ }^{1}$

RESUMO

No contexto histórico de intervenções em favelas na cidade do Rio de Janeiro, a década de 1990 é comumente destacada por ter iniciado um processo mais significativo, tanto em termos institucionais e técnicos quanto em termos de resultados práticos, não somente pelo número de favelas atendidas, mas pela visibilidade adquirida, em função dos agentes envolvidos. Este artigo apresenta as intenções e ações em torno de duas políticas públicas que, apontadas como continuidades do processo, incidiram recentemente sobre as favelas cariocas, o programa estadual de segurança pública "Unidades de Polícia Pacificadora - UPP" e o programa municipal de urbanização "Morar Carioca". 0 objetivo é abordar genericamente os discursos, também fundamentados na "integração" entre favela e cidade, além de revelar como, na prática, as lógicas do planejamento estratégico, que se implantaram na administração da cidade do Rio de Janeiro a partir de 1993, mesmo tendo sofrido inflexões, se mantiveram no período em destaque (2007-2016). Neste sentido, torna-se relevante a análise de procedimentos e também de documentos e informações relacionados aos programas*.

PALAVRA-CHAVE: Favelas, Políticas públicas; Rio de Janeiro

ABSTRACT

In the historical context of interventions in favelas in the city of Rio de Janeiro, the 1990s is commonly highlighted as having started a more significant process, both in institutional and technical terms and in terms of practical results, not only by the number of favelas served, but by the visibility acquired, depending on the agents involved. This article presents the intentions and actions around two public policies that, pointed as continuities of the process, have recently focused on the favelas of Rio de Janeiro, the state public security program Unidades de Polícia Pacificadora - UPP and the municipal urbanization program Morar Carioca. The goal is to approach the discourses, which are also based on the "integration" between favela and the city, and reveal how, in practice, the logic of strategic planning, implemented in the city of Rio de Janeiro since 1993, having suffered inflections, remained in the period in focus (2007-2016). In this sense, it becomes relevant the analysis of procedures and also of documents and information related to the programs.

KEY-WORDS: Favelas; Public policy; Rio de Janeiro.

*A abordagem aqui apresentada integrou parte da tese de doutorado intitulada "0 valor do lugar e o lugar do valor na formação e afirmação das favelas cariocas" (Tavares, 2016), desenvolvida entre março de 2012 e agosto de 2016, no âmbito do Programa de Pós-Graduação em Arquitetura e Urbanismo da Universidade Federal Fluminense - PPGAU-UFF, sob a orientação da Profa. Dra. Fernanda Furtado de Oliveira e Silva.

\section{Introdução}

O que a ação de forças de segurança do Estado tem a ver com a urbanização de favelas? Apesar de a violência praticada tanto por grupos criminosos quanto por policias interferirem na realização de obras e na implantação de projetos², esta questão é bem pouco debatida no desenvolvimento de propostas de intervenção física. Nestas, quando a segurança

\footnotetext{
1 Professora da Escola de Arquitetura e Urbanismo da Universidade Federal Fluminense. ricardalucilia@yahoo.com.br

2 Como exemplo pode ser citado o Museu a Céu Aberto no Morro da Providência, no âmbito do programa Favela-Bairro, que embora tenha sido totalmente executado do ponto de vista físico (entre 2003 e 2005), teve sua implantação efetiva interrompida, em função de uma série de ações da Polícia Militar e do Exército, envolvendo conflitos com o tráfico e a preparação para os Jogos Pan-Americanos de 2007 (ver depoimento de Lu Petersen em Freire et al, 2009, p. 113-129).
} 
pública é citada, comumente condicionam sua "solução" à atuação de instituições e instâncias específicas ${ }^{3}$. Apesar de seu impacto cotidiano no espaço da cidade, a correlação entre segurança e planejamento territorial dificilmente é estabelecida na elaboração e na análise de políticas urbanas. Isso ocorre por uma questão de campo de atuação, já que as intervenções físicas oficiais normalmente são "desenhadas" por arquitetos e urbanistas, muitas vezes distanciados dessa realidade social. Além disso, as propostas costumam estar associadas a uma prévia e homogênea leitura da favela e de seus moradores, carregados de históricos estigmas materiais e simbólicos, resultando no deslocamento das "soluções" em relação às específicas demandas do "objeto de intervenção".

Ou seja, ainda se percebe uma espécie de suavização ou desvirtuação dos reais impactos da violência urbana sobre diferentes setores da cidade. De fato, as questões que envolvem o tema segurança pública são complexas e polêmicas. Porém, as estatísticas demonstram que as chamadas "classes perigosas" são, contraditoriamente, as que mais sofrem violência letal, tendo as forças de segurança do Estado como seus principais algozes. Em 2015, a Anistia Internacional publicou um relatório sobre homicídios cometidos pela Polícia Militar na cidade do Rio de Janeiro e o perfil de suas vítimas, em quase sua totalidade homens (99,5\%), negros (70\%) e jovens (75\%) entre 15 e 29 anos. Os dados foram colhidos ao longo de dez anos e apontaram um pico de violência em 2007; embora os números tenham sofrido uma queda nos anos seguintes, voltaram a subir entre 2013 e 2014.

Figura 1: Número de homicídios decorrentes de intervenção policial na cidade do Rio de Janeiro, por Batalhão da Polícia Militar, 2014. Fonte: Anistia Internacional, 2015, p. 33.

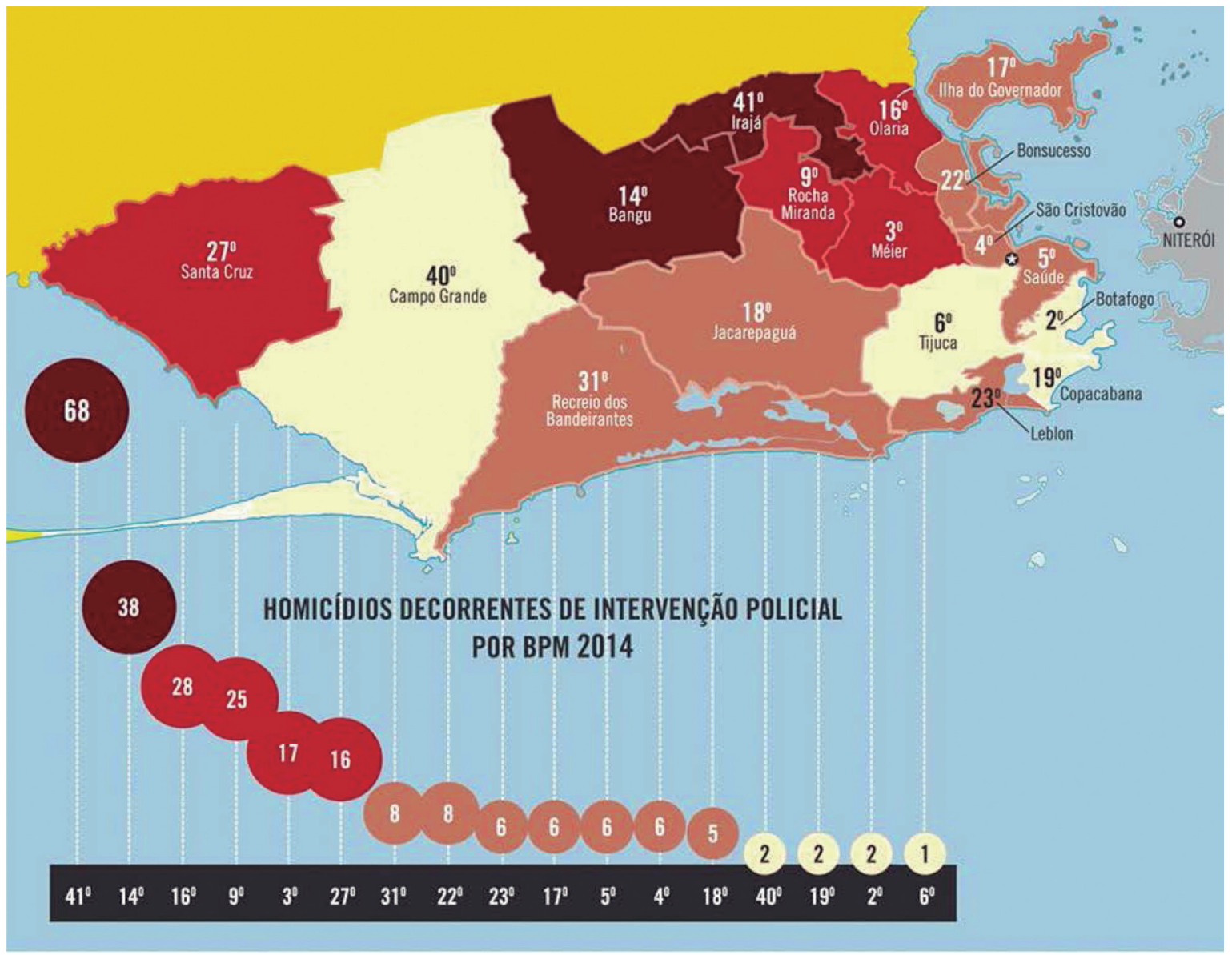

3 Os resultados do "Concurso Morar Carioca" (DVD Morar Carioca), realizado pelo IAB-RJ em 2010, demonstram que a segurança pública é tratada como uma condição prévia para viabilizar as intervenções. Com isso, cria-se um contrassenso, já que, na maioria das vezes, a efetividade da ação estatal para implantar infraestrutura e serviços públicos depende da ação estatal policial militar. 
O estudo também indicou uma média de 23 policiais mortos em serviço, por ano, no mesmo período, a maioria da PM. Portanto, além de algozes, os policiais também são vítimas, o que demonstra a urgência em se debater e rever as práticas policiais, além de se promover a interação entre políticas públicas de maneira mais ampla. Em 2014, as mortes decorrentes de intervenções policiais, também conhecidas como "autos de resistência" (figura jurídica que remonta à ditadura militar), e que na verdade são "execuções extrajudiciais", representaram $15,55 \%$ de todos os homicídios praticados na cidade do Rio de Janeiro, dado que revela a repetição de um padrão de uso desnecessário da força pela Polícia Militar (Anistia Internacional, 2015). Mas o drama cotidiano da violência policial tem endereço certo (ver Figura 1), orientado predominantemente pela condição de "informalidade" (ilegalidade, irregularidade, precariedade) de setores que podem ser considerados os mais vulneráveis da cidade, no que se refere à atuação benéfica das forças e dos poderes estatais.

Do ponto de vista da interação entre políticas de segurança e urbana, como a favela vem sendo tratada na cidade do Rio de Janeiro? Esta é a abordagem que se pretende esboçar neste artigo. Para isso, dois programas de intervenção em favelas do Rio de Janeiro foram selecionados: o programa estadual de segurança pública Unidades de Polícia Pacificadora, iniciado em 2008, e o programa municipal de urbanização Morar Carioca, iniciado em 2010. Além de documentos e publicações diretamente relacionados aos programas, utilizou-se como fontes para a análise as críticas de estudiosos e especialistas.

\section{As Unidades de Polícia Pacificadora}

Apesar de sua implantação na cidade do Rio de Janeiro ter sido iniciada no final de 2008, a oficialização do programa de segurança pública Unidades de Polícia Pacificadora - UPP ocorreu somente com o decreto no 42.787, de 06 de janeiro de 2011, quando já haviam sido instaladas treze unidades abrangendo inúmeras favelas. Segundo o conteúdo do decreto, as UPP foram criadas para a execução de ações especiais concernentes à "pacificação" e à "preservação da ordem pública", e destinadas a "aplicar a filosofia de polícia de proximidade" nas áreas designadas para sua atuação. É necessário ressaltar que a proposta de pacificação, em tese, pretendia interromper a lógica de "guerra às drogas" adotada até então nas ações policiais em favelas, que produzia consequências dramáticas no cotidiano dos moradores de favelas e da cidade como um todo.

Nos critérios estabelecidos pela Secretaria de Estado de Segurança, as UPP seriam instaladas em áreas formadas por "comunidades pobres", com "baixa institucionalidade" (sic) e "alto grau de informalidade", nas quais o oportunismo de grupos criminosos armados ostensivamente estivesse afrontando o Estado Democrático de Direito. Portanto, as UPP foram criadas para cumprirem o objetivo de "consolidar o controle estatal" e devolver à população a paz e a tranquilidade públicas necessárias ao "exercício da cidadania plena", além de "garantir o desenvolvimento tanto social quanto econômico".

O programa UPP apresentava a ambiguidade de querer orientar setores da cidade para o desenvolvimento pleno de suas liberdades civis (principalmente as econômicas), em muitos casos, por meio da coerção estatal. Em termos de distribuição espacial, entre dezembro de 2008 e maio de 2014 foram instaladas 37 UPP na cidade: 8 na Zona Sul, 23 na Zona Norte, 3 na Zona Oeste e 3 na Zona Central. Somente 1 se instalou fora da cidade, o Complexo da Mangueirinha, em Duque de Caxias, na Baixada Fluminense (ver Figura 2).

A UPP recebeu críticas por não se constituir, de fato, em um programa de segurança pública, mas sim uma estratégia voltada para os megaeventos e vinculada a um projeto empresarial de cidade. Os critérios de definição de sua localização estariam associados a essa estratégia, e como parte do plano de segurança traçado especificamente para a realização 
Figura 2: Mapa das 38 Unidades de Polícia Pacificadora instaladas entre 19/12/2008 e 23/05/2014.

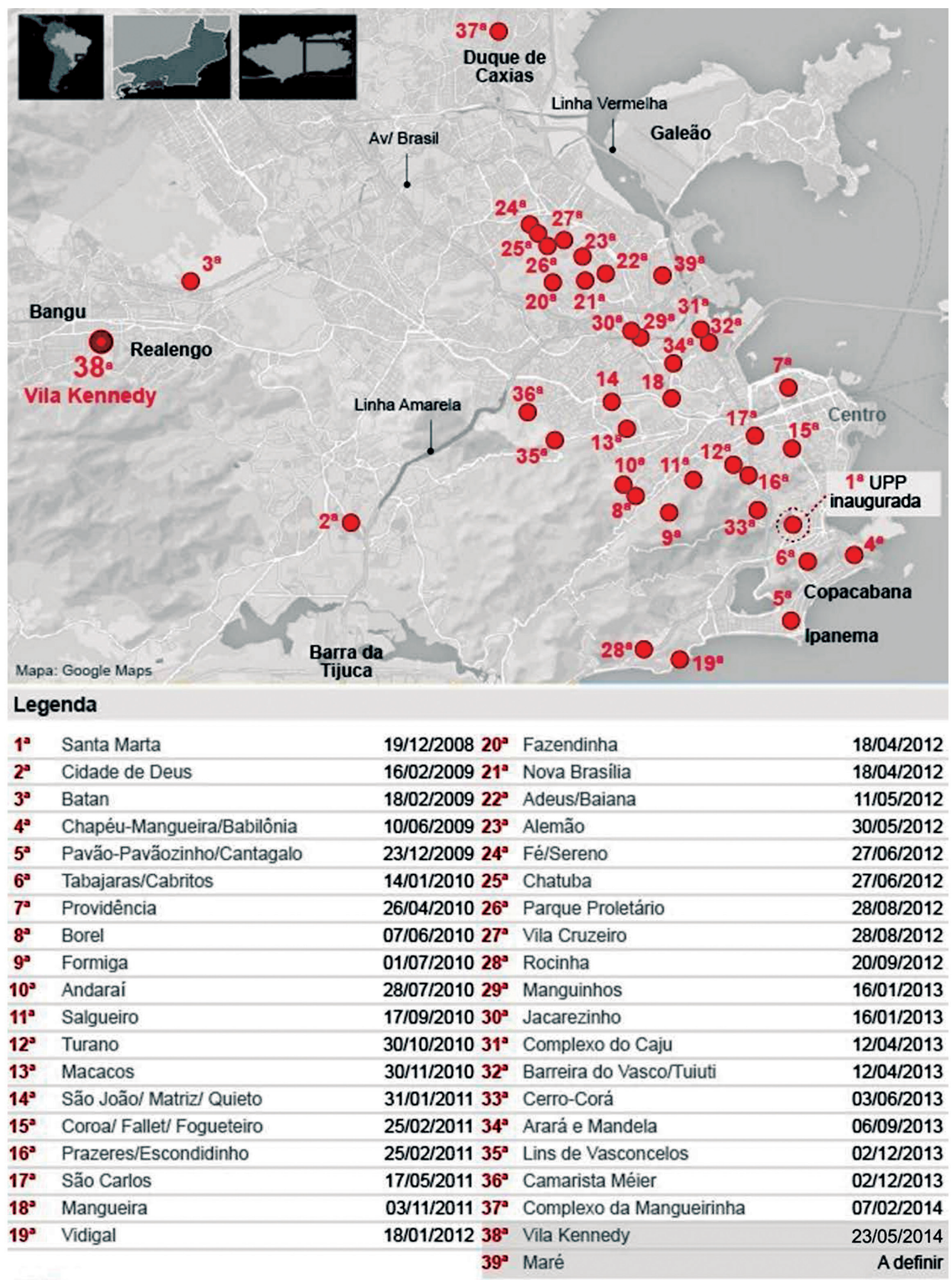


dos eventos esportivos; assim, sua continuidade estaria ameaçada ao final das Olimpíadas de 2016 (Valente, 2016). Sendo a violência urbana um problema estrutural, a intervenção promovida pelas UPP conseguiria no máximo tirar de cena o traficante ostensivamente armado. Além disso, os investimentos em políticas sociais foram insignificantes em comparação aos investimentos na ocupação militarizada. Neste sentido, uma política de segurança pública, para ser eficaz, deveria se preocupar em discutir a ilegalidade do comércio de drogas, verdadeira causa da ação violenta do tráfico, e também vincular-se a programas para resolver o também estrutural problema da desigualdade social.

Outra questão relevante a ser debatida e enfrentada diz respeito à atuação dos policiais que, em geral, tendiam a reproduzir as velhas práticas institucionalizadas, dominadas pela coerção e pela violência, muitas vezes associadas à corrupção. A ideia de "polícia de proximidade" estaria funcionando muito mais como retórica discursiva, que soa bem aos ouvidos da sociedade, do que propriamente na prática. Portanto, seria necessária uma profunda mudança na "cultura policial". Segundo Valente (2016), o programa das UPP se insere perfeitamente em duas tendências que são globais. Por um lado, a de um "urbanismo militar" e, por outro, a do empreendedorismo urbano. O urbanismo militar seria a extensão das concepções e tecnologias militares para o cotidiano das cidades, com sua aplicação na segurança pública, uma militarização da segurança. Ou seja, a existência de uma "indústria internacional da pacificação" e de uma ação militarizada, incorreria em inúmeras violações de direitos, desde a regulação de diversos aspectos da vida cotidiana até em desaparecimentos. Em muitos casos, a UPP também implicaria em desmobilização política dos moradores das favelas, em enfraquecimento das lideranças comunitárias.

Em paralelo à instalação das UPP se deu o crescimento da atuação das milícias no Rio de Janeiro. O relatório final da CPI das Milícias (ALERJ, 2008) apontava aproximadamente 170 áreas dominadas por esses grupos criminosos na cidade; e em 2012 já eram mais de 300 áreas $^{4}$. O relatório também apontou para a imbricada relação entre polícia, política e milícias, que estendem seus braços sobre o econômico e o territorial. O dado mais contundente quanto a isso está no fato de o mapa de homicídios advindos da atuação policial (Figura 1) ser em parte coincidente com o mapa de áreas de controle das milícias (Figura 3). Segundo o relator da CPI, a milícia não é um "poder paralelo", mas um "Estado leiloado", pois são agentes públicos da segurança dominando territórios e agindo com os instrumentos do Estado, por isso que é um crime mais organizado. Neste sentido, o tráfico nas áreas de favela, que é também violento e precisa ser enfrentado, não apresenta o mesmo grau de organização da milícia, que além de implantar o terror, também pratica o assistencialismo, por meio da implantação de centros sociais.

A UPP não interferiu no poder das milícias, pois sua incidência estaria relacionada à retomada de territórios estratégicos para um projeto de cidade (Freixo, 2012). E embora o mapa das UPP seja bastante revelador de suas reais intenções, o programa não pode (deve) ser desqualificado ou descontinuado, mas esta é uma análise importante para se entender e questionar sua não, ou pouca, incidência sobre áreas comandadas por milícias. A UPP foi instalada prioritariamente nos setores da cidade que são alvos de investimento do capital privado. Porém, mesmo onde foram implantadas, se não houver a promoção de ações para além da policial, o projeto tende a fracassar. No entanto, se a UPP enfraqueceu o varejo da droga, não enfraqueceu o poder das milícias, muito pelo contrário, teria beneficiado ainda mais a sua ampliação, como demonstra pesquisa realizada por Rodrigues (2014).

O tema segurança pública costuma ser associado a medidas de proteção, para assegurar que determinadas ameaças não se concretizem. A vida em aglomerações urbanas leva

4 O relator final da investigação promovida pela CPI, Marcelo Freixo, abordou a relação entre a atuação das milícias e a lógica das UPP, em sua participação no programa Roda Viva de 14/05/2012. Disponível em: https://www.youtube.com/watch?v=QdY5iEoGYUQ. Acesso em 24/02/2016. 
frequentemente à sensação de insegurança, à necessidade de proteção contra "estranhos", contra outros. $O$ outro é percebido como inimigo da paz, ou como ameaça a bens e valores materiais. A organização da cidade e das forças institucionalizadas pelo Estado, em grande parte, é orientada para garantir a segurança da propriedade privada e, em boa medida, a preservação de seus valores monetários. Neste sentido, há o controle das diferenças por meio das diferenciações de acesso aos bens e direitos coletivos, que em uma sociedade democrática deveriam ser igualitariamente garantidos pelo Estado.

Figura 3: Áreas controladas pelo tráfico de drogas e por milícias; e favelas com UPP, 2014.

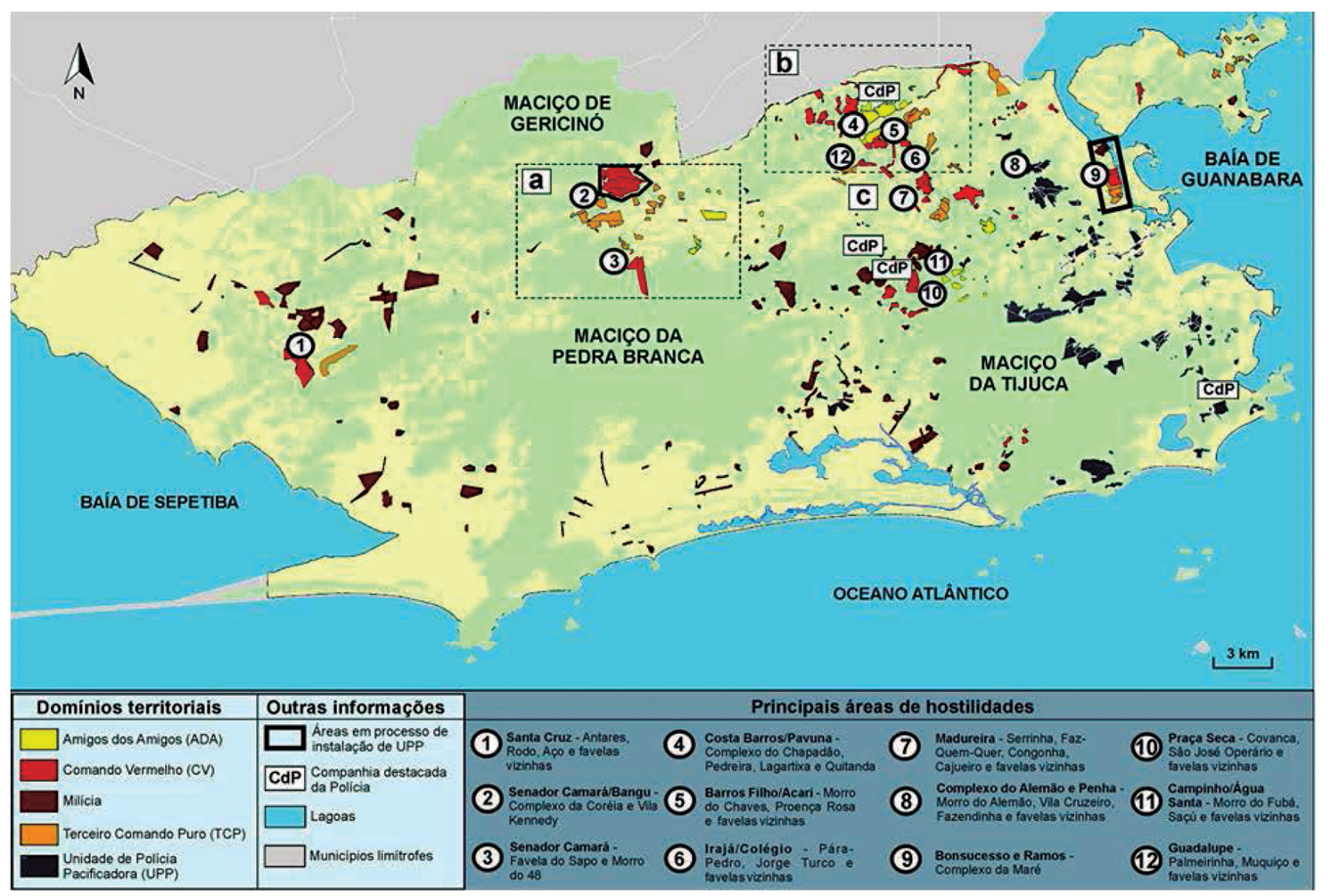

Fonte: https://capitalismoemdesencanto.files.wordpress.com/2014/04/edu-nvo-mapa.jpg. Acesso em 01/08/2016.

Não há dúvidas de que, sob qualquer ponto de vista, a implantação das UPP tem um caráter estratégico. Quanto ao papel do Estado, no discurso da "pacificação" aparece a urgência em intervir no poder coercitivo exercido pelos grupos que comandam o varejo das drogas instalado nas favelas cariocas. Por outro lado, o discurso da "polícia de proximidade" remete à alteração nas práticas de atuação da polícia, historicamente caracterizada pelo uso da força e também de mecanismos de coerção, não restrito somente aos criminosos. Mas há um terceiro discurso, o de "manutenção da ordem pública", de "consolidação do controle estatal", que esbarra na incapacidade dos poderes públicos e de grande parte da sociedade em reconhecer que o "exercício pleno da cidadania" não pode se basear na assunção ilusória de que as igualdades previstas pelo sistema legal podem ser alcançadas pela força.

Os discursos promovidos pela UPP foram positivamente difundidos e defendidos pelos segmentos da sociedade que, de fato, se beneficiaram pelo programa, notadamente os moradores de algumas das áreas de entorno das favelas "pacificadas". E também grande parte dos residentes em favelas tendia/tende a querer sua instalação, porém, a percepção de seus benefícios não é unânime nem inquestionável. As práticas discursivas das políticas de segurança são geralmente brandas, diferentes das práticas espaciais que, dependendo do contexto, podem ser bem agressivas e ostensivas. 


\section{0 programa Morar Carioca}

O Programa Municipal de Integração de Assentamentos Precários Informais - Morar Carioca foi lançado pela Prefeitura do Rio em julho de 2010. Incorporando a "visão de futuro" do Plano Estratégico 2009-2012, seu objetivo era "promover a inclusão social, através da integração urbana e social completa e definitiva de todas as favelas do Rio até o ano de 2020", como parte do legado dos grandes eventos que a cidade sediaria. A meta era investir $R \$ 8,5$ bilhões até 2020, sendo $R \$ 2,1$ bilhões até 2013 (ciclo 1); $R \$ 2,65$ bilhões de 2014 a 2016 (ciclo 2); e R\$ 3,75 bilhões de 2017 a 2020 (ciclo 3) .

Sabe-se, de antemão, que os equívocos produzidos ao longo do processo, e os pífios resultados alcançados, revelam uma prática muito distanciada dos discursos. Além disso, paralelamente, as favelas vêm sendo alvo de drásticas intervenções removedoras, justificadas pela prioridade dada às obras relacionadas aos grandes eventos. Portanto, trata-se de mera formalidade o tratamento do conteúdo das fontes oficiais ${ }^{6}$, importando muito mais a constatação de seu alinhamento com estratégias mais amplas de intervenções na cidade como um todo, visando à realização dos megaeventos.

Do ponto de vista técnico e institucional, os procedimentos adotados inicialmente seguiram a experiência do programa Favela-Bairro, com o lançamento do "Concurso Morar Carioca: conceituação e prática em urbanização de favelas", promovido pelo IAB-RJ", em parceria com a $\mathrm{SMH}$, a fim de selecionar as equipes que elaborariam os projetos para as favelas selecionadas. Segundo Paes e Magalhães, "no âmbito do Morar Carioca, urbanizar é tornar cidade", e o programa aproveitava as diversas experiências do Rio de Janeiro em décadas anteriores e buscava ampliá-las, para a superação plena desse "enorme desafio de integração social e urbanística".

O programa foi concebido para ser integrado ao Plano Municipal de Habitação de Interesse Social (concluído somente em 2012), do qual seria instrumento de regularização urbanística e fundiária, articulado a ações que contribuiriam para a integração efetiva das favelas atendidas, em consonância com o Plano Diretor (aprovado em 2011). A previsão era de que até 2020 fossem urbanizadas 251 unidades, correspondentes a 586 favelas.

O Morar Carioca contou com circunstâncias bem favoráveis para o seu desenvolvimento, se comparado ao programa Favela-Bairro, principalmente a ampla disponibilidade de recursos para as intervenções e para a construção de moradias populares. Tal possibilidade levou à "estratégia" de promover a diminuição do adensamento por meio de propostas de reassentamento para novas áreas. A criação de mecanismos de controle, monitoramento e ordenamento da ocupação e do uso do solo, discursivamente associada aos conceitos de sustentabilidade ambiental e moradia saudável, foi apresentada como uma das inovações do programa. Na verdade, as medidas de controle urbanístico tinham como finalidade coibir a expansão da ocupação, promovendo a recuperação dos territórios para a legalidade.

Acredita-se que qualquer avaliação do programa Morar Carioca tem que necessariamente ser pautada em três aspectos: 1) o que se prometeu e foi esboçado no concurso público realizado

\footnotetext{
5 Último informativo sobre o programa, em 22/01/2015, disponível na página oficial do programa no site da SMH: http://www.rio.rj.gov.br/web/smhc/conheca-o-programa. Acesso em 06/06/2014.

6 As fontes oficiais consultadas foram: o DVD de divulgação do resultado do Concurso Morar Carioca (2011); o Decreto no 36.388, de 29 de outubro de 2012, que instituiu o programa; os Planos Estratégicos 2009-2012 e 2013-2016; além dos sites oficiais do IAB-RJ e da SMH.

$7 \quad$ O concurso se realizou no final de 2010, com a seleção de 40 escritórios, e novamente o IAB-RJ comemorou a (posteriormente frustrada) oportunidade de arquitetos e urbanistas brasileiros ampliarem o mercado de trabalho e seu campo de atuação profissional.

8 Texto assinado pelo prefeito Eduardo Paes em coautoria com o então presidente do IAB-RJ, Sérgio Magalhães. Publicado no jornal O Globo, Opinião, 15/10/2010, p. 7.
} 
pelo (AB-RJ; 2) o que de fato se realizou, tendo no discurso os fundamentos do concurso e, na prática, as estratégias mais amplas do projeto de cidade; e 3) a efetiva intervenção nas favelas no período em análise, durante o qual se praticou, sem qualquer vínculo com o discurso da "integração urbana" ou do "legado social", a mais incisiva política de remoção desde o regime militar (1964-1985). Talvez fosse melhor ignorá-lo, fingir sua inexistência, dada a sua pouca efetividade, mas por trás de todo o aparato institucionalmente montado para inicialmente legitimar as intervenções havia o programa Favela-Bairro, que apesar de ter sofrido inúmeras críticas foi relativamente aceito e bem avaliado em muitas favelas.

Em relação ao primeiro aspecto, a maior parte das 40 equipes que foram selecionadas no concurso jamais foi convocada para iniciar os trabalhos. A Prefeitura justificou de diversas maneiras a não continuidade do programa, de problemas com os contratos, passando por falta de recursos, em função de outras prioridades, e falhas na criação de incentivos à iniciativa privada para a construção ou melhoria de moradias; e até mesmo a disputas políticas envolvendo a aliança entre PT e PMDB'. Em relatório de junho de 2011 (ver Tabela 1), a SMH apresentou o andamento de algumas obras, boa parte atribuída ao Morar Carioca, mas que já vinham sendo executadas antes mesmo da primeira gestão de Eduardo Paes.

As obras listadas na Tabela 1 não têm relação com os procedimentos vinculados ao concurso do IAB-RJ, pois somente em junho de 2012 foram contratados escritórios para desenvolver diagnósticos qualitativos de alguns agrupamentos de favelas, em parceria com o IBASE, ONG que assinou um acordo com a Prefeitura para estimular a participação comunitária e o controle social na definição dos projetos e obras do Morar Carioca ${ }^{10}$. A última notícia referente aos diagnósticos foi publicada em 27 de janeiro de 2013, em página específica no site do IAB-RJ' ${ }^{11}$. A parceria com o IAB havia sido encerrada ainda em 2012, o acordo com o IBASE cancelado em janeiro de 2013, e não foram divulgadas informações oficiais sobre a continuidade do programa com as concepções previstas no concurso. Em reportagem intitulada "Morar Carioca em compasso de espera" (O Globo, 18/05/2014), o então Secretário de Habitação, Pierre Batista, disse que não havia motivos para desânimo, pois o prazo para que os 40 projetos fossem colocados em prática só venceria em 2020.

Em relação ao segundo aspecto apontado para a avaliação, embora todas as concepções de intervenção e os procedimentos institucionais alardeados tenham sido abandonados menos de três anos após o lançamento do programa, o "nome fantasia" Morar Carioca foi adotado em obras municipais realizadas em favelas durante o período em análise. Porém, predominaram as estratégias de intervenção visando à adequação das favelas a lógicas e demandas de seu entorno e/ou da cidade como um todo, tendo como referência as obras relacionadas aos megaeventos.

Quanto ao terceiro aspecto, relacionado às intervenções que efetivamente vêm sendo realizadas nas favelas, em 25 de julho de 2010, dois dias antes do lançamento oficial do Morar Carioca, com o título "um novo plano para as favelas: programa a ser lançado por Paes prevê recontagem, controle, gabarito, conservação e choque de ordem", o jornal 0 Globo (Caderno Rio, p. 19) dava o tom das lógicas que predominariam sobre as favelas, que receberiam "tratamento idêntico ao recebido pela cidade formal". Todas teriam "gabarito fixado e limites demarcados" e seriam alvo de "choques de ordem em caráter permanente". Além disso, as favelas que estivessem em área de risco e não fossem urbanizáveis seriam removidas. A previsão era de que, até 2012, 123 favelas onde viviam 12.973 famílias em áreas de risco fossem erradicadas.

9 Notícia de 29/10/2013, disponível em https://riorealblog.com/2013/10/29/cade-o-morar-carioca. Acesso em 14/01/2014.

$10 \mathrm{http} / / /$ ibase.br/pt/noticias/ibase-lanca-morar-carioca-cidadania-ativa. Acesso em 04/08/2016.

11

http://www.iabrj.org.br/morarcarioca. Acesso em 04/08/2016. 
Tabela 1: Obras do "Morar Carioca” - até junho de 2011

\begin{tabular}{|c|c|c|c|c|}
\hline FAVELA & EXECUTOR & $\begin{array}{l}\text { VALOR } \\
\text { (R\$) }\end{array}$ & $\begin{array}{l}\text { PRAZO } \\
\text { (dias) }\end{array}$ & INÍCIO \\
\hline $\begin{array}{l}\text { Complexo de Manguinhos - } \\
\text { CHP2* }\end{array}$ & $\begin{array}{l}\text { Geomecânica-Tecnologia de Solos, } \\
\text { Rochas e Materiais }\end{array}$ & $10.774 .005,67$ & $\mathrm{~S} / \mathrm{I}$ & $07 / 12 / 2005$ \\
\hline $\begin{array}{l}\text { Complexo da Tijuca* } \\
\text { ( } 3 \text { áreas) }\end{array}$ & $\begin{array}{l}\text { Hécio Gomes Engenharia e Arkhe } \\
\text { Serviço de Engenharia }\end{array}$ & $63.176 .355,68$ & $\mathrm{~S} / \mathrm{I}$ & $\begin{array}{l}07 / 12 / 2005 \\
11 / 03 / 2008 \\
18 / 03 / 2008 \\
\end{array}$ \\
\hline $\begin{array}{l}\text { Complexo de Manguinhos - } \\
\text { Parque João Goulart* }\end{array}$ & $\begin{array}{l}\text { Geomecânica-Tecnologia de Solos, } \\
\text { Rochas e Materiais }\end{array}$ & $18.084 .980,46$ & $\mathrm{~S} / \mathrm{I}$ & $25 / 03 / 2008$ \\
\hline $\begin{array}{l}\text { Complexo de Manguinhos - } \\
\text { Vila Turismo* }\end{array}$ & Silo Engenharia & $21.827 .625,23$ & $\mathrm{~S} / \mathrm{I}$ & $25 / 03 / 2008$ \\
\hline $\begin{array}{l}\text { Complexo do Alemão - Nova } \\
\text { Brasília* }\end{array}$ & Hécio Gomes Engenharia & $45.370 .424,03$ & $\mathrm{~S} / \mathrm{I}$ & $20 / 05 / 2008$ \\
\hline $\begin{array}{l}\text { Complexo do Alemão - } \\
\text { Joaquim de Queiroz* }\end{array}$ & Dimensional Engenharia & $86.374 .741,10$ & $\mathrm{~S} / \mathrm{I}$ & $20 / 05 / 2008$ \\
\hline $\begin{array}{l}\text { Complexo de Manguinhos - } \\
\text { Mandela de Pedra* }\end{array}$ & Spil Serviços Técnicos de Engenharia & $30.916 .852,14$ & $\mathrm{~S} / \mathrm{I}$ & $01 / 09 / 2008$ \\
\hline Areal - Guaratiba* & $\begin{array}{l}\text { Chison Empreendimentos } \\
\text { Imobiliários }\end{array}$ & $5.852 .730,83$ & 330 & $01 / 09 / 2008$ \\
\hline Parque Alegria & Itaipu Construções e Saneamento & $5.424 .929,86$ & 360 & $22 / 06 / 2009$ \\
\hline Vila João Lopes & Rivel Construções & $5.329 .374,05$ & $\mathrm{~S} / \mathrm{I}$ & $29 / 06 / 2009$ \\
\hline Guarabu & Dimensional Engenharia & $\begin{array}{l}24.953 .404,01 \\
15.392 .496,09\end{array}$ & $\begin{array}{l}540 \\
360\end{array}$ & $\begin{array}{l}13 / 07 / 2009 \\
13 / 06 / 2011\end{array}$ \\
\hline $\begin{array}{l}\text { Azevedo Lima / Santos } \\
\text { Rodrigues }\end{array}$ & Volume Construções e Participações & $17.659 .925,02$ & $\mathrm{~S} / \mathrm{I}$ & $10 / 08 / 2009$ \\
\hline $\begin{array}{l}\text { Colônia Juliano Moreira - } \\
\text { Áreas } 1 \text { e 1A / Entre Rios* }\end{array}$ & $\begin{array}{l}\text { Consórcio RC Vieira / Giver / } \\
\text { Construtora WV / Volume } \\
\text { Construções e Participações }\end{array}$ & $\begin{array}{l}32.392 .551,09 \\
17.016 .615,50\end{array}$ & $\begin{array}{l}540 \\
450\end{array}$ & $\begin{array}{l}15 / 12 / 2009 \\
28 / 07 / 1998\end{array}$ \\
\hline São Carlos /Mineira & Volume Construções e Participações & $16.535 .547,29$ & $\mathrm{~S} / \mathrm{I}$ & $10 / 05 / 2010$ \\
\hline Barão / São José Operário & Volume Construções e Participações & $34.746 .775,87$ & 720 & $10 / 11 / 2010$ \\
\hline Morro da Coroa & Volume Construções e Participações & $18.125 .885,66$ & 540 & $16 / 11 / 2010$ \\
\hline $\begin{array}{l}\text { Vila Caramuru / Mineiros / Vila } \\
\text { Amizade }\end{array}$ & Hécio Gomes Engenharia & $23.221 .862,06$ & 540 & $20 / 12 / 2010$ \\
\hline $\begin{array}{l}\text { Nova Jerusalém / Pedreira / } \\
\text { Parque Nova Cidade de Acari }\end{array}$ & $\begin{array}{l}\text { Andrade Gutierrez e Hécio Gomes } \\
\text { Engenharia }\end{array}$ & $149.960 .024,66$ & 1.080 & $24 / 01 / 2011$ \\
\hline Morro da Providência & $\begin{array}{l}\text { Consórcio RioFaz Odebrecht, OAS e } \\
\text { Carioca }\end{array}$ & $131.087 .283,70$ & 1.080 & $16 / 02 / 2011$ \\
\hline $\begin{array}{l}\text { Colônia Juliano Moreira - Vila } \\
\text { dos Idosos }\end{array}$ & Vit Cenografia e Construções & $3.363 .065,65$ & 240 & $08 / 04 / 2011$ \\
\hline Chapadão/ Chico Mendes & Delta Construções & $109.365 .938,17$ & 1.080 & $25 / 04 / 2011$ \\
\hline Babilônia / Chapéu Mangueira & Dimensional Engenharia & $43.347 .818,97$ & 720 & $02 / 05 / 2011$ \\
\hline $\begin{array}{l}\text { Colônia Juliano Moreira - Área } \\
2 \mathrm{~A}\end{array}$ & Consórcio RC Vieira / Premag & $31.730 .541,90$ & 510 & $02 / 05 / 2011$ \\
\hline $\begin{array}{l}\text { Complexo do Lins - Nossa } \\
\text { Senhora da Guia }\end{array}$ & Volume Construções e Participações & $31.326 .706,24$ & 720 & $02 / 05 / 2011$ \\
\hline $\begin{array}{l}\text { Colônia Juliano Moreira - EDI } \\
\text { Leila Diniz }\end{array}$ & Vit Cenografia e Construções & $3.271 .705,14$ & 240 & $06 / 05 / 2011$ \\
\hline \multirow[t]{2}{*}{ Complexo da Penha - $1^{\mathrm{a}}$ etapa } & Construtora Andrade Gutierrez & $143.331 .077,82$ & 1.080 & $06 / 06 / 2011$ \\
\hline & VALOR TOTAL & $139.961 .243,89$ & & \\
\hline
\end{tabular}

Fonte: PCRJ, 2011b.

$\mathrm{Na}$ mesma reportagem havia opiniões divergentes de "especialistas", dentre elas, uma afirmava que "a urbanização é bem-vinda e as remoções também", esperando que a prefeitura tivesse previsto "a retirada de comunidades localizadas em áreas de preservação ambiental permanente". A previsão/sugestão se consumou e o Plano Diretor de 2011 não somente condenou a relação/sobreposição de áreas de especial interesse social e ambiental, como mapeou os "conflitos" a serem resolvidos. 
Para Gonçalves (2013, p. 348), há uma distinção marcante entre o Morar Carioca e o programa Favela-Bairro no que se refere aos reassentamentos. Este último previa que fossem evitados ao máximo e, quando necessários, não deveriam ultrapassar a $5 \%$ do total de moradias. Exemplos recentes como o do Morro da Providência, que chegou a ter quase um terço da favela sob o risco de remoção, demonstram a guinada nos critérios.

Figura 4: Grupos de favelas que seriam beneficiadas pelo Morar Carioca.

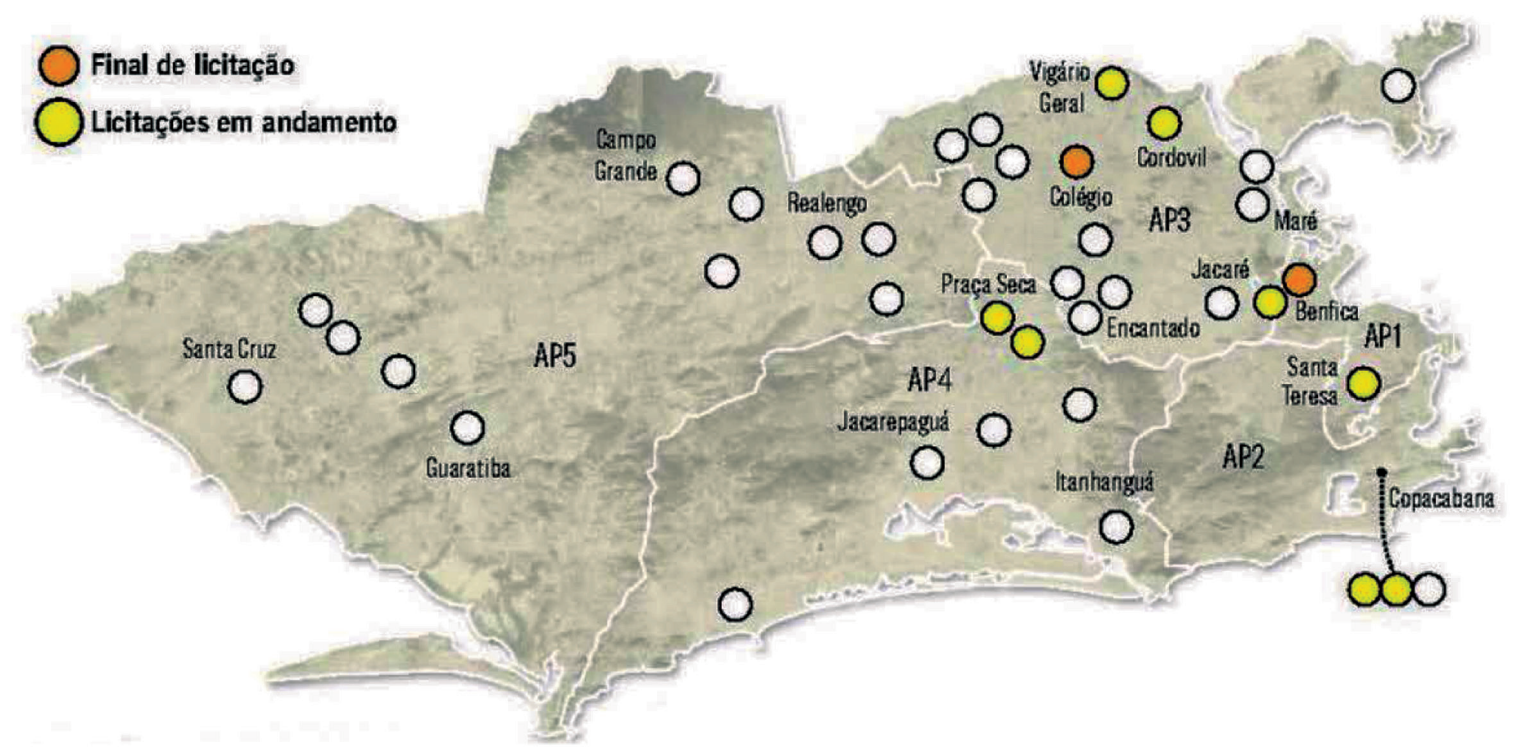

Fonte: O Globo, Caderno Rio, 18/05/2014, p. 13.

Além disso, o governo Paes pautou o retorno do princípio de que as favelas devem ser urbanisticamente congeladas, com os parâmetros de ocupação e os critérios de regularização fundiária instituindo uma lógica de controle efetivo da expansão horizontal e vertical, sem ao menos cogitar a possibilidade de um crescimento regulado, tentando respeitar padrões de ocupação existentes. Tal princípio pode ser observado no conteúdo do Decreto no 33.648, de 11 de abril de 2011, que revogou todos os anteriores que regulavam a construção em favelas declaradas como Áreas de Especial Interesse Social - AEIS. Para Gonçalves (2013, p. 349), anacronicamente, o decreto proíbe qualquer nova construção ou reforma nas edificações existentes em favelas. Segundo o autor, mesmo que sua aplicação seja improvável, o conteúdo revela as mudanças atualmente em vigor.

Cabe ressaltar que, no período em análise, as remoções foram intensamente praticadas pelos poderes públicos na cidade do Rio de Janeiro. Entre 2009 e 2015, por diferentes motivos, 22.059 famílias (aproximadamente 77.206 pessoas) foram removidas. Do número apresentado, estima-se que 4.120 famílias tenham sido removidas em função de obras diretamente vinculadas aos megaeventos. Outras permaneceram sob a mesma ameaça. De acordo com o último relatório do Comitê Popular da Copa e Olimpíadas do Rio de Janeiro (2015, p. 20), embora estivessem claras as motivações relacionadas ao projeto "Rio Cidade Olímpica", as informações foram mascaradas por justificativas como prevenção de risco e preservação ambiental. Portanto, parece não ter sido por acaso que o Plano Diretor de 2011 previu mecanismos que viabilizassem juridicamente tal discurso.

Por fim, é importante citar o programa UPP Social, também a cargo da Prefeitura, e que no Plano estratégico 2013-2016 foi apresentado como uma iniciativa a fim de assegurar a consolidação da paz e efetivar a integração urbana, social e econômica das favelas ao conjunto da cidade. O desafio era estender a qualificação da provisão dos bens e serviços públicos às áreas pacificadas. Uma unidade de gestão vinculada ao Instituto 
Pereira Passos seria dedicada à coordenação de investimentos e políticas municipais, à articulação de parcerias com outras esferas de governo, setor privado e sociedade civil, e à criação de canais de participação junto às lideranças e moradores.

\section{Análise geral dos programas UPP e Morar Carioca}

Os dois programas apresentaram a "integração" como fundamentos do discurso. Porém, é importante destacar que as propostas tanto de integração social (UPP) quanto de integração urbanística (Morar Carioca) se apresentaram vinculadas a outra: a de integração econômica. A instalação das unidades de polícia pacificadora precedeu e, de certa maneira, condicionou a implantação do Morar Carioca. Os procedimentos adotados após a instalação da UPP deram ênfase à regularização/formalização da favela por meio da expansão da cobertura de serviços, com a incorporação de novos clientes às empresas concessionárias. Estudos recentes como os de Cunha \& Mello (2012) e Pilo' (2015) abordam os conflitos advindos desse processo de "priorização" da regularização urbanística por meio da substituição de práticas "informais" de acesso aos serviços, em especial após a instalação das UPP.

Dependendo da localização das favelas, notadamente as da Zona Sul, a combinação da pacificação com a formalização do acesso aos serviços, que impõe um considerável aumento nos gastos familiares, levou imediatamente a dois efeitos simultâneos: a valorização imobiliária, no entorno e no interior das favelas; e a ameaça de remoção branca, pela mudança no perfil dos moradores, de acordo com a renda.

O Secovi-Rio acompanhou as primeiras instalações de UPP em favelas cariocas e, em 2012, calculou uma valorização média de 30 a 40\% nos bairros de sua vizinhança (Figura 5). O "efeito UPP" sobre o mercado imobiliário continuou sendo registrado em dezembro de 2013, quando era apontado $15 \%$ de crescimento no preço médio dos imóveis da cidade, desde 2008, diretamente vinculado à política de segurança ${ }^{12}$. Também em dezembro de 2013 se apontava o crescimento entre 25 e 30\% dos negócios em áreas pacificadas ${ }^{13}$, por exemplo, com a formalização de "biroscas", que se transformaram em restaurantes, muitos dos quais passando a integrar os guias gastronômicos e turísticos da cidade. $O$ incentivo ao empreendedorismo nas favelas contou com o acompanhamento da UPP Social e o apoio do SEBRAE-RJ. Apesar de muito festejado na mídia, tal processo aparentemente não teve seu alcance ampliado, inclusive com "retrocessos", parcialmente devido às mudanças na conjuntura política e econômica do país, mas também em função das especificidades das propostas oficiais para determinadas áreas.

O "pacote de benefícios" proporcionados pelas UPP integrou uma sequência de reportagens de O Globo, em dezembro de 2013, abordando a diminuição do índice de homicídios $^{14}$, que nas favelas pacificadas era de 8,7 por 100 mil habitantes, enquanto no Brasil era de 24,3 por 100 mil, não havendo estado ou capital com taxa abaixo de 10 . Levantamento inédito, feito a partir de estatísticas do Instituto de Segurança Pública (ISP), revelou que em sete das 29 favelas pacificadas analisadas - Santa Marta, Chapéu Mangueira, Babilônia, Ladeira dos Tabajaras, Morro dos Cabritos, Formiga e Salgueiro -

12 Fonte:http://oglobo.globo.com/rio/efeito-upp-na-valorizacao-de-imoveis-chega-1511021226\#ixzz3m1RoSECQ. Acesso em 15/01/2016.

13 Fonte:http://oglobo.globo.com/rio/negocios-em-areas-pacificadas-crescem-ate-30-em-5-anos11009521\#ixzz3m1VuaIqM. Acesso em 15/01/2016.

14 Fonte:http://oglobo.globo.com/rio/taxa-de-homicidios-em-upps-quase-13-da-media-nacional11004359\#ixzz3m1WZFUxz. Acesso em 15/01/2016. 
não foi registrado sequer um assassinato no ano de $2012^{15}$. Nas outras 22 favelas com UPP houve 22 mortes, mas a tendência era de queda, pois foram seis a menos que em 2011.

Figura 5: UPP e valorização imobiliária em 2012, registro do SECOVI-RIO para imóveis residenciais de dois quartos, antes e depois da ocupação.

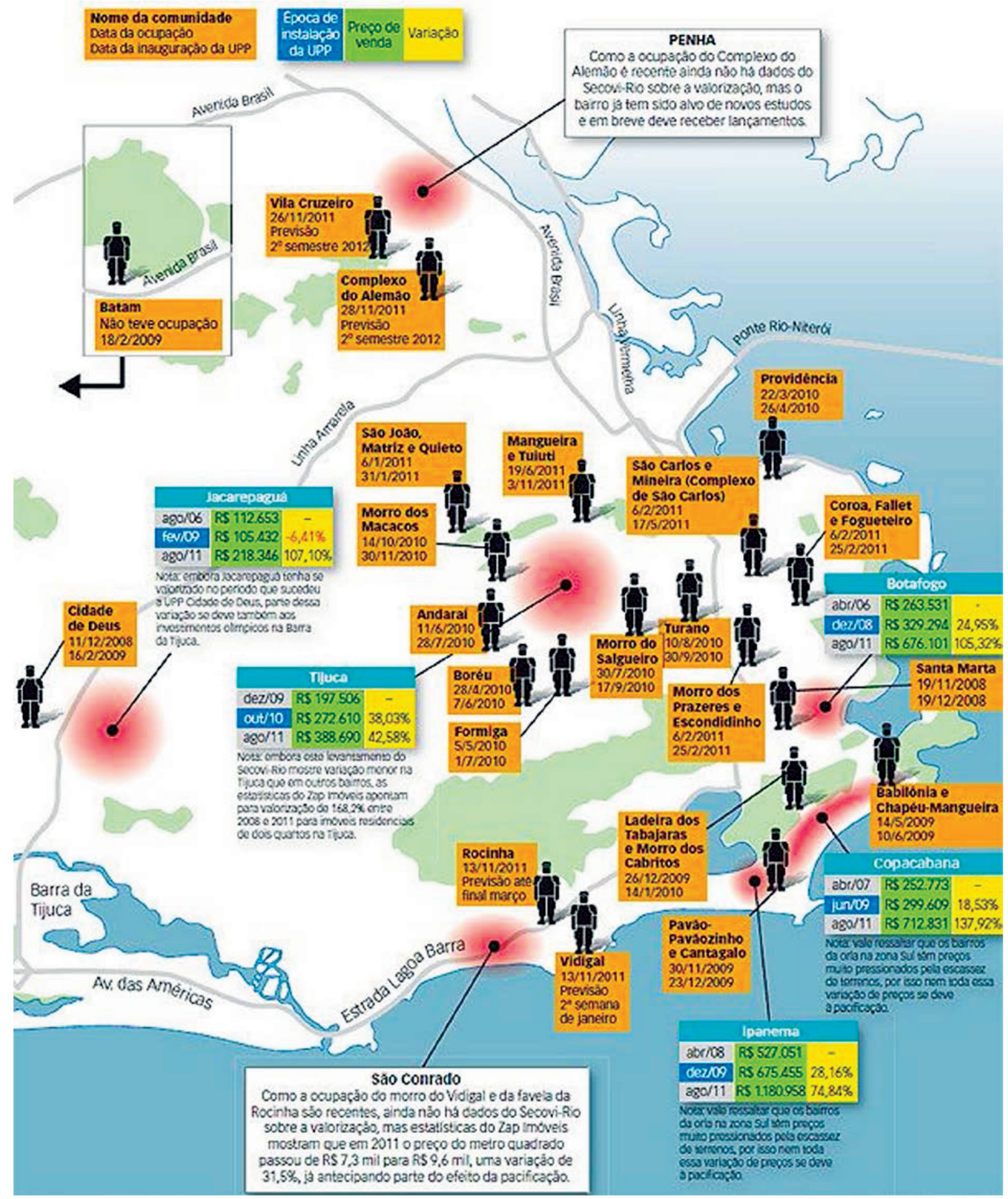

Fonte http://construcaomercado.pini.com.br/negocios-incorporacao-construcao/127/o-efeito-upp-a-pacificacao-de-favelas-no-

rio-282612-1.aspx. Acesso em 17/09/2015.

15 Em dezembro de 2013 já haviam sido implantadas 36 UPP, que beneficiavam diretamente 540,5 mil pessoas. Os dados levantados na reportagem levavam em conta apenas os registros de 18 UPP, que abrangiam 29 favelas. 
A sequência de reportagens também incluiu uma entrevista com o então secretário de segurança do estado do Rio de Janeiro, José Mariano Beltrame (em 13/12/2013) ${ }^{16}$, que defendeu reformas urbanas profundas nas favelas pacificadas, como a implantação de infraestrutura de saneamento e abertura de vias. Porém, o secretário vinculou as melhorias urbanísticas diretamente ao "tema das remoções", afirmando que:

Hoje remoção é tabu, é palavra proibida, porque colocaram ideologia no debate. Hoje há conhecimento, tecnologia e solução urbanística para dar esta guinada definitiva.

Mirando o futuro, Beltrame indagava o que seria da favela em vinte anos, condicionando a mudança efetiva da realidade à exigência de que algumas famílias trocassem de endereço "para a obra passar". Assim, os ganhos seriam irreversíveis para dezenas de milhares de famílias pobres, fora "os ganhos indiretos para a cidade". Mas para fazer a "intervenção de verdade" era necessária a "discussão das remoções", o assunto precisava entrar em pauta. O secretário disse que o governo do estado não estava autorizado a "mover uma palha", porque os conflitos na justiça paralisavam tudo. E não era mais possível conceber o Rio sem as UPP, "sem os alívios que elas trouxeram". Mas, sozinho, o executivo estadual não tinha força para "mudar a cara da favela. Mudar de verdade", pois havia centenas de ações judiciais impedindo os avanços. Citou o teleférico da Providência, que estava pronto, mas uma ação judicial proibia o seu funcionamento.

O secretário apontava para a necessidade de intervir no adensamento da favela e na sua estrutura de ocupação, de certa maneira apontando sua transformação formal como condição para o sucesso da UPP, tendo como espelho o restante da cidade. É um discurso que reforça as propostas de urbanização produzidas pelo "Morar Carioca", algumas com intervenção drástica na estrutura física existente, como a sugerida para o Morro da Providência.

Em outra reportagem de O Globo $(12 / 12 / 2013)^{17}$, especialistas como Alba Zaluar, Cláudio Ferraz e Ignácio Cano apontavam para o que logo depois se confirmou como o início da crise de desmoralização da polícia, ou seja, de legitimidade do poder público/policial; consequentemente, de credibilidade do programa, em função da evidenciação de casos nos quais se constatava a adoção de práticas policiais distintas às enunciadas nos discursos oficiais ${ }^{18}$. Ainda contavam negativamente a não efetivação dos serviços e projetos sociais complementares à ação policial, além das complexas disputas e os muitos interesses contrários ao sucesso da UPP.

Os sinais de esgotamento das práticas discursivas que fundamentaram o programa se acentuaram com a, posteriormente frustrada, ocupação do Complexo da Maré, no início de abril de 2014. A estratégia montada se configurou em uma operação de guerra, que expôs a opção pelo uso voluntário da força e do aparato coercitivo do Estado, em negação ao discurso da pacificação e da polícia de proximidade.

Segundo Itamar Silva ${ }^{19}$, o programa Unidades de Polícia Pacificadora foi pensado para pequenas favelas no entorno do "cinturão olímpico", mas logo se tornou um "desejo de consumo do carioca", morador ou não de favelas, como solução para a violência. O Estado

16 Fonte: http://oglobo.globo.com/rio/beltrame-sobre-5-anos-de-upp-daqui-20-anos-que-sera-da-favela11056774\#ixzz3m1TJfD5p. Acesso em 15/01/2016.

17 Fonte: http://oglobo.globo.com/rio/especialista-upps-precisam-ter-confianca-da-populacao-para-obterresultados-11044789\#ixzz3m1V8857u. Acesso em 15/01/2016.

18 Casos como o desaparecimento de Amarildo, morador da Rocinha, e a onda de protestos que aconteceram em meados de 2013 colocaram em xeque a UPP e o próprio governo estadual.

19 Entrevista de Itamar Silva a Martha Neiva Moreira, do Canal IBASE, em 26/03/2014. Disponível em: http://www.canalibase.org.br/o-projeto-das-upps-nunca-teve-definicao-clara. Acesso em 02/10/2015. 
incorporou essa demanda, mas fragilizou a proposta ao não adequá-la a situações mais difíceis de enfrentar, sem perder o respeito aos direitos humanos. Por outro lado, a UPP se tornou muito rapidamente uma bandeira política e a sociedade acreditou cegamente no seu sucesso. Não houve tempo para maturação e nem disposição para análises e avaliações críticas, o que poderia ter resultado em ajustes necessários. O próprio Estado acreditou nisso, incensado pela mídia a uma experiência exitosa, expondo-a para o país e para o mundo como uma alternativa de enfrentamento à violência e ao tráfico nas favelas.

Itamar destacou que ainda não se podia dizer que não deu certo, mas havia sérias críticas a serem feitas, já que a modelagem da UPP exigiria um efetivo policial muito grande. Por exemplo, na favela Santa Marta (primeira UPP instalada, em dezembro de 2008) foi previsto inicialmente um grupo de 120 policiais, para aproximadamente 6 mil moradores. Ficou claro que a dimensão do efetivo anunciada ali não suportaria a expansão do projeto. Ou seja, para uma favela de 60 mil habitantes seria necessária sua multiplicação por dez, e isso não ocorreria. Outra questão é que os policiais que foram para a Santa Marta eram novos e, portanto, não "viciados na corrupção", e o Estado também não conseguiu sustentar isso durante muito tempo, pois não formou uma quantidade suficiente de novos policiais. Em decorrência, surgiu o problema de, na mídia, se construir uma imagem do bom policial (o novo) contraposta à do mau policial (o antigo), o que resultou em uma disputa interna dentro da corporação. De um lado, os novos e bons policiais e, de outro lado, os antigos taxados de corruptos. Porém, os antigos policiais estão em toda a cidade e são eles que têm o controle sobre a rede do tráfico e que conhecem a dinâmica que alimenta a corrupção. Para eles, ser policial é ter uma arma na mão e partir para o enfrentamento, e o que estava colocado para a UPP era bem diferente disso.

Para Itamar, ainda não se conseguiu construir uma política de segurança diferenciada nas favelas e está mais do que claro que a UPP e o tráfico convivem hoje no mesmo território. 0 próprio secretário de segurança já havia dito que as UPP iriam retirar os armamentos, mas não acabar com o tráfico. $O$ armamento visível se consegue retirar, mas isso não significa que o Estado consiga algum controle sobre o território, que depende muito do tamanho da favela e dos pactos que se estabelecem. Há interesses, geografias e disputas em jogo.

Ou seja, existem demandas e dinâmicas locais que os policiais da UPP têm que entender, não havendo clareza sobre o papel que devem cumprir para respeitar as lutas que já eram travadas. Uma efetiva política de segurança, portanto, deveria promover a construção antecipada de um diálogo com as organizações e lutas locais, pois nem tudo é dinâmica estabelecida pelo ou para o funcionamento do tráfico, como se imagina a partir de uma visão externa e preconcebida da favela.

Como já é possível constatar, embora o "tema das remoções" viesse rondando a mídia em falas de especialistas e de autoridades (como o secretário estadual de segurança), o programa Morar Carioca não podia se pautar diretamente em propostas radicais de intervenção sem fundamentar-se em justificativas plausíveis. Tais justificativas foram construídas por meio do discurso do risco geológico, que ameaçavam a segurança e a vida dos próprios moradores de favela; e o discurso da preservação ambiental, lançado como responsabilidade coletiva para a garantia da sustentabilidade urbana.

Um terceiro discurso foi produzido no contexto de exceção criado pela realização de megaeventos na cidade: o da grande oportunidade de transformação efetiva da realidade, que dependia do sacrifício de alguns para benefício de todos. As transformações urbanas pensadas como possibilidade de encurtamento do caminho para realizações maiores, ou seja, a previsão e a antecipação do futuro.

Neste sentido, o discurso da integração se tornou mais poderoso com o lançamento de uma meta de intervenção que alcançaria todas as favelas da cidade em curto período de tempo. De certa maneira, a utilização inicial do mesmo modus operandi do programa Favela-Bairro, 
que embora tenha frustrado expectativas, não produziu maiores problemas além de ter sido bem sucedido e aceito em muitas favelas, como já foi dito, serviu como boa estratégia de convencimento e de obtenção de apoio de diversos segmentos da sociedade civil.

Além do mais, é notório que a inserção nas redes de consumo de bens e serviços públicos não é totalmente rechaçada pelos moradores de favelas, como se difunde no senso comum, mas reivindicada como um direito, porém com tratamento diferenciado, inclusive em função do longo período de manutenção do déficit urbano pela falta de investimento do Estado. No entanto, quando se parte da prioridade de formalizar sem atender a uma lógica de diferenciação, o resultado previsível é um impacto brusco (tendendo para o negativo) sobre as dinâmicas socioeconômicas estabelecidas. Portanto, a análise dos programas de intervenção deve passar fundamentalmente pelo questionamento do que, de fato, pretendem garantir, modificar ou produzir. Deve-se também atentar para sobre quais aspectos de sua realidade os moradores de favelas querem igualmente garantias, mudanças ou novas realizações. Racionalidades externas e internas se cruzam e interferem na avaliação da efetividade das políticas públicas sobre as favelas. 


\section{Referências bibliográficas}

ALERJ. Relatório Final da Comissão Parlamentar de Inquérito destinada a investigar a ação de milícias no âmbito do Estado do Rio de Janeiro. Rio de Janeiro: Assembleia Legislativa do Estado do Rio de Janeiro, 2008.

ANISTIA INTERNACIONAL. Você matou meu filho! Homicídios cometidos pela Polícia Militar na cidade do Rio de Janeiro. Rio de Janeiro: Anistia Internacional, 2015.

COMITÊ POPULAR DA COPA E OLIMPÍADAS DO RIO DE JANEIRO. Olimpíadas Rio 2016: os jogos da exclusão. Megaeventos e Violações dos Direitos Humanos no Rio de Janeiro. Dossiê do Comitê Popular da Copa e Olimpíadas do Rio de Janeiro. Rio de Janeiro, 2015.

CUNHA, Neiva Vieira da; MELLO, Marco Antonio da Silva Mello. A UPP e o processo de urbanização na favela Santa Marta: notas de campo. In MELLO, Marco Antonio da Silva Mello et al (orgs.). Favelas cariocas: ontem e hoje. Rio de Janeiro: Garamond, 2012, p. $433-475$.

FREIRE, Américo; FREIRE-MEDEIROS, Bianca e CAVALCANTI, Mariana (Orgs.). Lu Petersen: militância, favela e urbanismo. Rio de Janeiro: Editora FGV, 2009.

FREIXO, Marcelo. Participação no programa Roda Viva, de 14/05/2012. Vídeo disponível em: https://www.youtube.com/watch?v=QdY5iEoGYUQ. Acesso em 24/02/2016.

GONÇALVES, Rafael Soares. Favelas do Rio de Janeiro: história e direito. Rio de Janeiro: Pallas; Ed. PUC-Rio, 2013.

PILO', Francesca. La régularisation des favelas par l'électricité. Un service entre Etat, marché et citoyenneté. Ecole Nationale des Ponts et Chaussées, 2015. (Tese de Doutorado)

PREFEITURA DA CIDADE DO RIO DE JANEIRO. Pós 2016: o Rio mais integrado e competitivo 2013-2016. Rio de Janeiro: PCRJ, $2013 a$.

Lei Complementar no 111 de $1^{0}$ de fevereiro de 2011. Plano Diretor de Desenvolvimento Urbano Sustentável do Município do Rio de Janeiro. Rio de Janeiro, 2011a.

Programa Morar Carioca: Obras em andamento - Fase 1. Rio de Janeiro: Secretaria Municipal de Habitação, $2011 b$.

Pós 2016: o Rio mais integrado e competitivo 2009-2012. Rio de Janeiro: PCRJ, 2009.

RODRIGUES, Eduardo. Rio-verão-2014: quando extinguir o Comando Vermelho passa a ser a novíssima solução para a questão da violência urbana carioca. Publicado em 10 de abril de 2014. Disponível em: https://capitalismoemdesencanto.wordpress.com/2014/04/10/rioverao-2014-quando-extinguir-o-comando-vermelho-passa-a-ser-a-novissima-solucaopara-a-questao-da-violencia-urbana-carioca-1a-parte. Acesso em 01/08/2016.

TAVARES, Ricarda Lucilia Domingues. O valor do lugar e o lugar do valor na formação $e$ afirmação das favelas cariocas. Niterói-RJ: Universidade Federal Fluminense, 2016. (Tese de Doutorado)

VALENTE, Julia. UPPs: governo militarizado e a ideia de pacificação. Rio de Janeiro: Revan, 2016. 